\title{
Correlation transfer for integrate and fire models with finite postsynaptic potentials
}

\author{
Robert Rosenbaum*, Kresimir Josic \\ From Nineteenth Annual Computational Neuroscience Meeting: CNS*2010 \\ San Antonio, TX, USA. 24-30 July 2010
}

Correlations between the spiking activity of neurons have implications for coding and the dynamical behavior of neuronal networks [1-3]. A fundamental problem in the study of correlations in neuronal networks is that of correlation transfer: given neurons receiving correlated inputs, what is the correlation between their output spike trains? Earlier analytical approaches have addressed this question by modeling subthreshold activity as a continuous diffusion process [4-7]. Such models are obtained in the limit of a large number of inputs with infinitesimal postsynaptic response amplitudes. We address the problem of correlation transfer for models with finite postsynaptic responses.

We use random walk models to derive analytical results, then verify these results with current and conductance based leaky integrate-and-fire models. This approach yields intuitive insights into the mechanisms of correlation transfer in a variety of settings.

We first investigate correlation transfer for the simple and analytically tractable perfect integrate-and-fire (PIF) model, which approximates more realistic models in drift dominated regimes. We find that the PIF model preserves correlations perfectly under very general assumptions. We then extend the PIF model in order to consider the effects of synaptic noise and recurrent coupling on correlation transfer in drift dominated regimes.

We also derive an analytical expression to explain and quantify the reduction of correlations in fluctuation dominated regimes. We then use an analytically tractable leaky random walk model to explore the implications of this expression.

\section{Acknowledgements}

This work was supported by NSF Grants DMS-0604429 and DMS-0817649 and a Texas ARP/ATP award.

\footnotetext{
* Correspondence: robertr@math.uh.edu

Mathematics, University of Houston, Houston, TX 77004, USA
}

Published: 20 July 2010

\section{References}

1. Averbeck BB, Latham PE, Pouget A: Neural correlations, population coding and computation. Nat Rev Neurosci 2006, 7:358-366.

2. Biederlack J, Castelo-Branco M, Neuenschwander S, Wheeler D, Singer W, Nikolic D: Brightness induction: rate enhancement and neuronal synchronization as complementary codes. Neuron 2006, 52:1073-1083.

3. Sompolinsky H, Yoon H, Kang K, Shamir M: Population coding in neuronal systems with correlated Noise. Phys Rev E Stat Nonlin Soft Matter Phys 2001, 64(5 Pt 1):051904.

4. de la Rocha J, Doiron B, Shea-Brown E, Josi'c K, Reyes A: Correlation between neural spike trains increases with firing rate. Nature 2007, 448:802-806.

5. Moreno-Bote R, Parga N: Auto- and crosscorrelograms for the spike response of leaky integrate-and-fire neurons with slow synapses. Phys Rev Lett 2006, 96:028101.

6. Ostojic S, Brunel N, Hakim V: How connectivity, background activity, and synaptic properties shape the cross-correlation between spike trains. J Neurosci 2009, 29:10234-10253.

7. Vilela RD, Lindner B: Comparative study of different integrate-and-fire neurons: spontaneous activity, dynamical response, and stimulusinduced correlation. Phys Rev E Stat Nonlin Soft Matter Phys 2009, 80(3 Pt 1):031909.

doi:10.1186/1471-2202-11-S1-P11

Cite this article as: Rosenbaum and Josic: Correlation transfer for integrate and fire models with finite postsynaptic potentials. $B M C$ Neuroscience 2010 11(Suppl 1):P11.
Submit your next manuscript to BioMed Central and take full advantage of:

- Convenient online submission

- Thorough peer review

- No space constraints or color figure charges

- Immediate publication on acceptance

- Inclusion in PubMed, CAS, Scopus and Google Scholar

- Research which is freely available for redistribution

Submit your manuscript at www.biomedcentral.com/submit
C Biomed Central 